\title{
Climate and environmental change drives Ixodes ricinus geographical expansion at the northern range margin
}

Solveig Jore ${ }^{1 *}$, Sophie O Vanwambeke ${ }^{2}$, Hildegunn Viljugrein 1,3, Ketil Isaksen ${ }^{4}$, Anja B Kristoffersen ${ }^{1,5}$, Zerai Woldehiwet ${ }^{6}$, Bernt Johansen ${ }^{7}$, Edgar Brun ${ }^{1}$, Hege Brun-Hansen ${ }^{8}$, Sebastian Westermann ${ }^{9}$, Inger-Lise Larsen ${ }^{1}$, Bjørnar Ytrehus ${ }^{1}$ and Merete Hofshagen ${ }^{1}$

\begin{abstract}
Background: Global environmental change is causing spatial and temporal shifts in the distribution of species and the associated diseases of humans, domesticated animals and wildlife. In the on-going debate on the influence of climate change on vectors and vector-borne diseases, there is a lack of a comprehensive interdisciplinary multi-factorial approach utilizing high quality spatial and temporal data.

Methods: We explored biotic and abiotic factors associated with the latitudinal and altitudinal shifts in the distribution of Ixodes ricinus observed during the last three decades in Norway using antibodies against Anaplasma phagocytophilum in sheep as indicators for tick presence. Samples obtained from 2963 sheep from 90 farms in 3 ecologically different districts during 1978 - 2008 were analysed. We modelled the presence of antibodies against A. phagocytophilum to climatic-, environmental and demographic variables, and abundance of wild cervids and domestic animals, using mixed effect logistic regressions.

Results: Significant predictors were large diurnal fluctuations in ground surface temperature, spring precipitation, duration of snow cover, abundance of red deer and farm animals and bush encroachment/ ecotones. The length of the growth season, mean temperature and the abundance of roe deer were not significant in the model.
\end{abstract}

Conclusions: Our results highlight the need to consider climatic variables year-round to disentangle important seasonal variation, climatic threshold changes, climate variability and to consider the broader environmental change, including abiotic and biotic factors. The results offer novel insight in how tick and tick-borne disease distribution might be modified by future climate and environmental change.

Keywords: Tick, Range expansion, Climate change, Climatic variability, Ixodes ricinus, Anaplasma phagocytophilum, Bush encroachment, Ecotones, Global environmental change, Remote sensing

\section{Background}

Ticks, currently the main vectors of arthropod-borne pathogens in Europe and a major threat to human and animal health [1], are increasing in abundance and expanding their distribution limits [2]. Identifying the multiple factors that may influence vector distribution is a prerequisite in predicting health risks for humans and

\footnotetext{
* Correspondence: solveig.jore@vetinst.no

${ }^{1}$ Norwegian Veterinary Institute, Ullevålsveien 68, P.O.Box 750, Sentrum 0106, Oslo, Norway

Full list of author information is available at the end of the article
}

animals. The limits of the range, as is found in Norway, are ideal grounds to unravel factors delineating population persistence or extinction. However, the factors and/ or scale of changes at these extreme limits might not reflect the changes at the core distribution of the vector or pathogen [3].

Ixodes ricinus, a three-host tick species which is freeliving with brief feeding periods between the different tick stages (larvae, nymph and adult) [4] transmits protozoal, viral and bacterial pathogens, several of which are zoonotic. As I. ricinus is ectothermic, its fitness is strongly 
temperature dependent [5], but its activity and survival are also closely related to the degree of relative humidity [6,7]. Global climate change is affecting overall mean temperatures and factors such as precipitation, rainfall, and vegetation, which in turn might affect the geographic distribution of ticks and other arthropods [2,8]. Beyond changes in the absolute levels of environmental variables, the probable changes in variability between seasons have also been highlighted $[9,10]$. Although these climatic changes could influence the life cycle of I. ricinus, we lack clear evidence for a consistent association between tick abundance and a warmer and wetter climate [11]. Other environmental variables such as landscape characteristics and abundance of hosts are also important drivers of tick population dynamics $[12,13]$ and might therefore modify or mask climatic factor effects [14,15].

Landscape and hosts are also subject to climatic factors, as well as to agriculture, forestry and wildlife management practices [16]. Indeed, because of the multiplicity of interactions between factors influencing the tick abundance and dynamics, the effects of climate change on ticks and tick-borne diseases are often controversial and subject of debate [17]. A recent distribution map of I. ricinus in Norway [18] shows a shift in latitudinal and altitudinal distribution. During the last three decades there have been considerable changes in temperature, landscape, vegetation, demography, agricultural/forestry practice and the density of host animals in Norway.

The aim of the present interdisciplinary study was to explore the multi-factorial influence of biotic and abiotic factors in driving the expansion of $I$. ricinus. While spatially and temporally detailed tick distribution data is unavailable for the past, the prevailing distribution of $I$. ricinus in Norway corresponds to the distribution of Anaplasma phagocytophilum [19]. The bacterium A. phagocytophilum causes Tick-borne fever (TBF), which is the most common vector-borne pathogen of sheep and cattle in northern Europe [20]. Recent studies indicate that different strains of $A$. phagocytophilum may affect different host species and there may be variation in the pathogenicity of strains, even those affecting the same species of host [20]. A. phagocytophilum also causes human granulocytic anaplasmosis (HGA), which is now widely recognised as an emerging zoonotic tick-borne disease [21,22].

Changes in tick exposure can be indirectly measured by detecting infections or evidence of infection in hosts susceptible to tick-borne pathogens. As sheep are susceptible hosts to A. phagocytophilum [23], antibodies to A. phagocytophilum should be good indicators of the presence of $I$. ricinus, the only known vector of TBF in northern Europe [20]. Even though the prevalence of A. phagocytophilum in sheep also could be influenced by the rates of infection in the tick vector, density of hosts and the strains of $A$. phagocytophilum found within a geographic area, changes in the prevalence of A. phagocytophilum in sheep should reflect changes in tick exposure $[24,25]$. We studied changes in exposure to I. ricinus as proxied by the number of sheep seropositive for TBF.

All the explanatory variables were smoothed on a decadal basis to even out year to year variation. We focused on factors affecting survival and reproduction success of ticks, namely climate, bush encroachment, demography, abundance of cervids and farm animals.

\section{Methods}

\section{Study design}

Three study districts were selected in Southern Norway (INLAND, COAST and FJORD) which differ with respect to historical tick presence, topography, demography of human and animal population, bush encroachment, presence of cervids and degree of climate change. Sheep serum samples from farms residing in the three districts were divided into 3 timespans; timespan 1 (1978-1989), timespan 2 (1990-1999) and timespan 3 (2000-2008). Several environmental, climatic and demographic variables were generated for the same timespans as the serum samples, and their effect was tested using statistical models.

\section{Collection of samples and sample size}

The serum samples belong to the sample and culture collection of the Norwegian Veterinary Institute (NVI), and were collected randomly, throughout the year, as part of the national surveillance programs (see Additional file 1). Each of 90 farms was sampled once (except for four farms which were sampled two (2), three (1) and four (1) times). A total of 2963 samples were collected. Assuming a seroprevalence of $A$. phagocytophilum of $10 \%$ in sheep flocks, we aimed for 300 samples per timespan within each district to be able to estimate prevalence with a $95 \%$ confidence limit and accuracy of 10\% $\pm 3.39 \%$ (CI 0.069-0.140) using the R package Epi.

\section{Study area}

Five municipalities were selected in the districts of AustAgder and Vest-Telemark (INLAND), an inland area previously thought to be free of I. ricinus [26,27]. Seven municipalities were selected in the district of Jæren (COAST), an exposed coastal and agricultural district with no or low abundance of ticks in the past $[26,27]$. Two municipalities were selected in the district of Haugalandet (FJORD), a more sheltered fjord and valley district, where $I$. ricinus has been common since the first surveys $[26,27]$. I. ricinus is now present in all municipalities that constitute these three districts [18]. A description of the landscape, vegetation and general 
climate in INLAND, COAST and FJORD is given in Additional file 1.

\section{Laboratory method}

An enzyme-linked immunosorbent assay (ELISA) was used to test for the presence of antibodies against $A$. phagocytophilum in sheep [28,29], with minor modifications (Details given in Additional file 1). The absorbance value of each test sample was expressed as a ratio of positivity (PP). The cut-off point between positive and negative samples was $0.20 \mathrm{PP}$. This was based on the mean PP value +2 standard deviations of several negative ovine sera [29].

\section{Definition of the outcome variable}

The unit of observation was a single serum sample from an individual sheep. The outcome variable was the presence $(\geq 0.20 \mathrm{PP})$ or absence $(<0.20 \mathrm{PP})$ of antibodies to A. phagocytophilum in each serum [29].

\section{Climatic data}

As climatic variables tend to be spatially homogenous over short distances, each study district was divided in three zones depending on elevation and distance to the sea. Three representative farms were then chosen in each zone, resulting in 27 farms for which climatic variables were derived. Climatic variables were also generated for the rough grazing used by 22 farms at a different elevation or more than $10-20 \mathrm{~km}$ away from the farm. Further details are given in Additional file 1.

\section{Remote sensing data}

Landsat images covering the 3 study districts were retrieved for the summer of either 1984 or 1988, and 2006 (Landsat 5TM). A binary map of bush encroachment from the 80's to 2006 was produced. Buffer zones of a $500-\mathrm{m}$ radius were established around farms and rough grazing locations. The total area of bush encroachment, the number of patches found within each zone, and their mean area were calculated (See Additional file 1). The bush encroachment variables were assumed to reflect a continuous process during the study period and were assumed to be independent of timespan.

\section{Demographic factors, grazing systems and the animal populations}

The number of bagged cervids (moose, roe deer and red deer), number of sheep over one year of age, number of livestock farms and the human population in the municipalities were retrieved from Statistics Norway for 1980-2008. Changes in these factors during the study period are displayed in Additional file 1: Figures S2, S3 and S4 and Table S2.

The grazing system of each farm was identified on the basis of information given by the farmers and/or by the municipal agricultural offices. Two types of grazing systems were encountered: infield grazing in fenced pastures near or around the farm and rough grazing in semi-natural forest/mountain pastures away from the farm during the summer and autumn. The altitude ranges of the grazing areas are given in Additional file 1: Table S1. Fifty-eight farms (64\%) grazed the sheep on mountain pasture whilst 32 farms (36\%) kept the sheep on fenced pastures near the farm. All the farms in INLAND used mountain pastures at high elevation (mean 880 masl), whilst in COAST and FJORD 52\% and 77\% of the farms respectively used rough grazing, at a far lower altitude (mean 318 masl and mean 515 masl, respectively).

\section{Preprocessing of climate and temporal variables}

Eleven of the twenty-two climatic variables for farm and pasture level were calculated on a monthly basis and the rest annually (Table 1 ). Highly correlated variables were identified using the first and second components of principal component analyses, and were subsequently grouped using means. For example, as the relative humidity variables for the winter months were highly correlated, they were grouped for the months OctoberMarch (RHmean ${ }_{\text {Oct-Mar }}$ ). The aggregated climatic variables were not highly correlated (all pairwise Pearson correlation coefficients $<0.7$ ), and were assumed to account for the main seasonal patterns of the respective climatic variables. All temporal predictor variables were aggregated over a ten-year timespan matching the timespan defined for the outcome variable. For example, the moose population from the 1980's (timespan 1), represent the mean bagged moose population during the period 1980-1989, 1990's (timespan 2) defined as 1990-1999 and 2000's (timespan 3) as 2000-2008. For the climatic variables the definition of the timespan period took into account tick biology. Ticks might complete the life cycle in three to six years. Therefore, climatic variables were aggregated for extended periods starting 4 years prior to the sampling timespans.

\section{Statistical analyses}

The prevalence data at individual sheep level (presence or absence) were fitted with a mixed effect logistic regression. In order to account for spatial and temporal structure in the data, the variables "municipality" and "timespan" were designated as random effects in the mixed effect logistic regression. Four municipalities were combined with a neighbouring municipality such that each random effect level contained data from at least two farms. The multivariable regression was performed with the function lmer (lme4 package in R) and family binomial. All analyses were performed in $\mathrm{R}$ version 2.14.0 [30]. Generalized additive models [31] were used to identify possible nonlinear relationships or skewed 
Table 1 Definition of all climate and temporal variables used in the analyses

Variable for both infield and rough grazing level

Moose

Red Deer

Roe Deer

Sheep

NuFarms

F_masl

Humans

Area

Timespan

$\mathrm{Nu}$ _patch

Meanarea_p

Area shrubi

TMeanJan; TMeanFeb; etc.....

TMeanSDJan; TMeanSDFeb; etc...

TminJan; TminFeb; etc..

TmaxJan; TmaxFeb; etc..

GrowSeasDays

RRSumJan; RRSumFeb; etc..

$\mathrm{RH}>$ 70DaysJan; RH > 70DaysFeb; etc..

RHMeanJan; RHMeanFeb; etc..

SatDefMeanJan.; SatDefMeanFeb; etc..

SatDef < 5DaysJan; SatDef < 5DaysFeb; etc..

SnostartDays

SnoEndDays

SnoDepth $\geq 2$ Days

SnoDepth1-2Days

SnoDepth2-20Days

SnoDepth > 20Days

Snosum

GSTminJan

GSTmaxJan

FTDays-SnoDepth $\geq 2$

FTDays-SnoDepth $<2$

BlackFrdays

TDecr $\div 5<$ DaysJan; TDecr $\div 5<$ DaysFeb; etc..

TDecr $\div 10<$ DayJan; TDecr $\div 10<$ DayFeb; etc..

\section{Definition}

The number of bagged moose in the municipality (divided by size of municipality)

The number of bagged red deer in the municipality (divided by size of municipality)

The number of bagged roe deer in the municipality (divided by size of municipality)

The number of sheep in the municipality (divided by size of municipality)

The number of farms in the municipality (divided by size of municipality)

The meters above sea level at which the farm is situated

The number of inhabitants in the municipality (divided by size of municipality)

Denoting district 1,2 and 3 (INLAND,COAST and FJORD)

Denoting the 3 decades; timespan 1(80s), timespan 2(90s) and timespan 3 (00s)

Number of patches of bush encroachment in a 500-m radius

Mean area of patches of bush encroachment intersected by a 500-m radius $\left(\mathrm{m}^{2}\right)$

Total area covered by patches of bush encroachment intersected by a 500-m radius $\left(\mathrm{m}^{2}\right)$

Daily mean air temperature; monthly basis

Daily mean air temperature standard deviation; monthly basis

Lowest daily mean air temperature; monthly basis

Highest daily mean air temperature; monthly basis

The length of the growing season. (1)

Precipitation sum, monthly basis

Number of days with relative humidity $>70 \%$; monthly basis

Mean relative humidity; monthly basis

Mean saturation deficit; monthly basis. (2)

Number of days with saturation deficit $<5 \mathrm{mmHg}$; monthly basis

Number of days in a hydrological year* to snow depth $\geq 2 \mathrm{~cm}$ (3)

Number of days in a hydrological year* to snow depth $\Gamma \ddot{Y} \leq 2 \mathrm{~cm}$ in spring

Number of days in a hydrological year* with snow depth $\geq 2 \mathrm{~cm}$

Number of days in a hydrological year* with snow depth of $1-2 \mathrm{~cm}$

Number of days in a hydrological year* with snow depth of 2-20 cm

Number of days in a hydrological year* with snow depth $>20 \mathrm{~cm}$

Sum of snow depth (cumulative) per hydrological year*

Lowest daily ground surface temperature (GST); monthly basis

Highest daily ground surface temperature (GST); monthly basis

Number of days in a hydrological year* with freeze-thaw events at ground surface with snow depth $\geq 2 \mathrm{~cm}$. (4)

Number of days in a hydrological year* with freeze-thaw events at ground surface with no snow cover or snow depth $<2 \mathrm{~cm}$.

Number of days in a hydrological year* with black frost; daily GST $<0^{\circ} \mathrm{C}$ and ground bare of snow or snow depth $<2 \mathrm{~cm}$.

Number of days per month where temperature decrease in GST from a day to the next day are $>5^{\circ} \mathrm{C}$.

Number of days per month where temperature decrease in GST from a day to the next day are $>10^{\circ} \mathrm{C}$. 


\section{Table 1 Definition of all climate and temporal variables used in the analyses (Continued)}

\begin{tabular}{ll}
\hline TIncr + 5<DaysJan; TIncr + 5<DaysFeb; etc.. & Number of days per month where temperature increase in GST from a day \\
& to the next day are $>5^{\circ} \mathrm{C}$. \\
TIncr + 10<DaysJan; TIncr + 10<DaysFeb; etc.. & Number of days per month where temperature increase in GST from a day \\
& to the next day are $>10^{\circ} \mathrm{C}$.
\end{tabular}

(1) Number of days between the end of the first continous 4-day period with a $24 \mathrm{~h}$ mean air temperature $>5^{\circ} \mathrm{C}$ and the beginning of the last continous 4-day period with a $24 \mathrm{~h}$ mean air temperature $>5^{\circ} \mathrm{C}$. (2) Saturation Deficit (SDF) is a measure of air humidity (in mmHg); it is the difference between actual and maximum vapour content: $\mathrm{SDF}=(1-\mathrm{RH} / 100) \times 4.9463 \times \mathrm{e}(0.0621 \mathrm{~T})$. $\mathrm{RH}$ is the daily mean $\mathrm{RH}(\%), \mathrm{T}$ is the daily mean air temperature $\left({ }^{\circ} \mathrm{C}\right)$. (3) For all $\mathrm{SnoDays}$ variables and $\mathrm{SnoSum}$ the number of days refers to the hydrological year. (4) A freeze-thaw event is defined as when daily Ground Surface Temperature (GST) Crosses $0^{\circ} \mathrm{C}$ from one day to the next. *A hydrological year is from 1 September -31 August.

variable distributions. These exploratory analyses suggested second-order polynomial terms for four variables, and categorisation of a skewed variable.

We used a two-step procedure for model selection. Initially we fitted single variable mixed effect logistic regressions of all potential predictor variables with municipality and timespan as random effects and kept only variables with a $\mathrm{p}$-value $\leq 0.20$ for further model selection. Twenty-eight of 67 variables were kept for the farm/infield and 18 of 67 variables for the rough grazing (see Additional file 1: Table S3). A stepwise backward model selection approach was applied to build the full model, using Akaike Information Criteria (AIC) for model selection [32]. Highly correlated variables (Pearson correlation coefficient $\geq 0.7$ ), were not included in the full model at the same time. A difference of $\leq \pm 2$ of the AIC value was regarded as equivalent models and the most parsimonious model was then chosen. Residuals of the final model were plotted against all explanatory variables, and mapped, in order to explore any potential remaining systematic patterns. The predictive power of the final model, with random effects included, was assessed by plotting predicted farm prevalence against observed farm prevalence. To measure the accuracy of the model, area under the curve (AUC) of a ROC curve was calculated. The ROC curve is a plot of the sensitivity versus (1- specificity) for all thresholds [33].

\section{Results}

\section{Antibodies against Anaplasma phagocytophilum}

A total of 1543 samples (52\%) were positive for antibodies against $A$. phagocytophilum (Figure 1). Seropositive sheep were detected in all areas and during all timespans (Additional file 1: Table S1 and Table S2). There was an increase in the number of positive animals over time for FJORD, an increase for the last time span in COAST whilst there was a decrease over time in positive samples collected from INLAND (Table 2). FJORD showed the highest number of positive animals (Table 2).

\section{Climatic variables}

The general trends in essential climatic variables for period 1981-2010 are described in Additional file 1:
Figure S1. Figure 2 displays some variables significant in the multivariable model (Table 3). INLAND is characterized by higher inter-annual and decadal climate variability and shows more variations between the timespans. COAST had the most prominent and homogenous changes. The greatest increase was in the number of days per year with high day-to-day fluctuations in ground surface temperature (TDecr $\div 5<$ Days $_{\text {Jan-Dec }}$, definitions in Table 1). FJORD had the least prominent changes over time compared to INLAND/COAST, but still at a level of $>20 \%$ change for several variables.

\section{Vegetation changes}

Bush encroachment was observed in all study areas. INLAND had the most pronounced bush encroachment of farm surroundings and rough grazing. On average 10 patches of bush encroachments intersected a $500 \mathrm{~m} \mathrm{ra}$ dius around the farm, totalling on average about 5ha (6.4\% of the buffer area). On the other hand, $500 \mathrm{~m}$ radii around rough grazing locations intersected on average 8 patches of bush encroachment, totalling an average 3.5 ha $(4.5 \%)$. INLAND also had the largest mean size of encroached patches, with 0.5 ha near farms and 0.3 ha in rough grazing locations. COAST, a more intensively used region where agricultural land covers most of the area, had on average 2 patches of bush encroachment intersecting a $500 \mathrm{~m}$ radius, totalling less than 1 ha $(1.3 \%)$ on average in both farm and pasture locations. COAST also had the smallest average mean size of patches, below 0.2 ha both around farms and in pastures. FJORD presented an intermediate situation, with 4 and 6 patches intersected on average in farms and on rough grazing respectively, totalling just over 1ha (1.3\%) around farms and just over 2 ha $(2.5 \%)$ in rough grazing locations.

\section{Results for multivariable regression}

The model that best predicted A. phagocytophilumprevalence in the three districts over time included large daily fluctuations in temperature in general, and in certain months of the year, seasonal precipitation changes, duration of snow cover, bush encroachment, abundance of red deer and density of farms with animals (Table 3 ). The six variables explaining most of the 

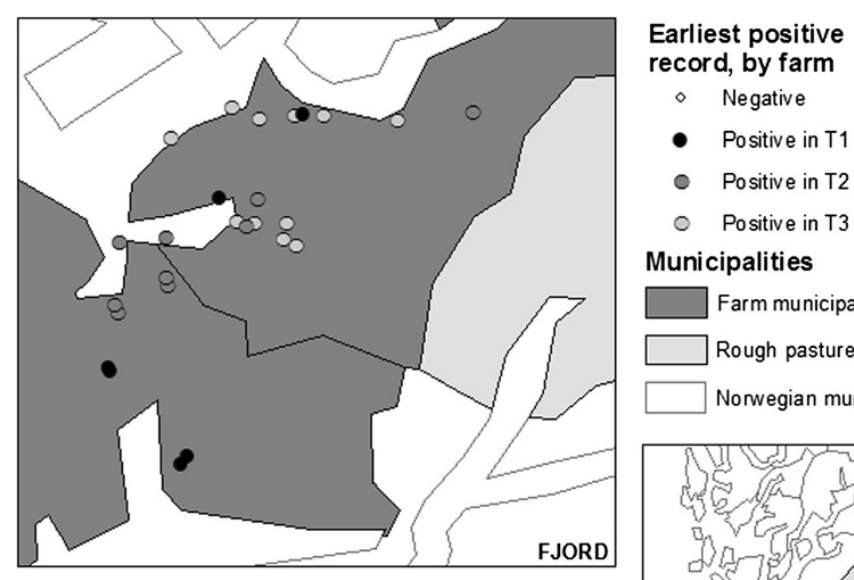

- Positive in T1

- Positive in $\mathrm{T} 2$

- Positive in T3

\section{Municipalities}

$\square$ Farm municipalities

Rough pasture municipalities

Norwegian municipalities
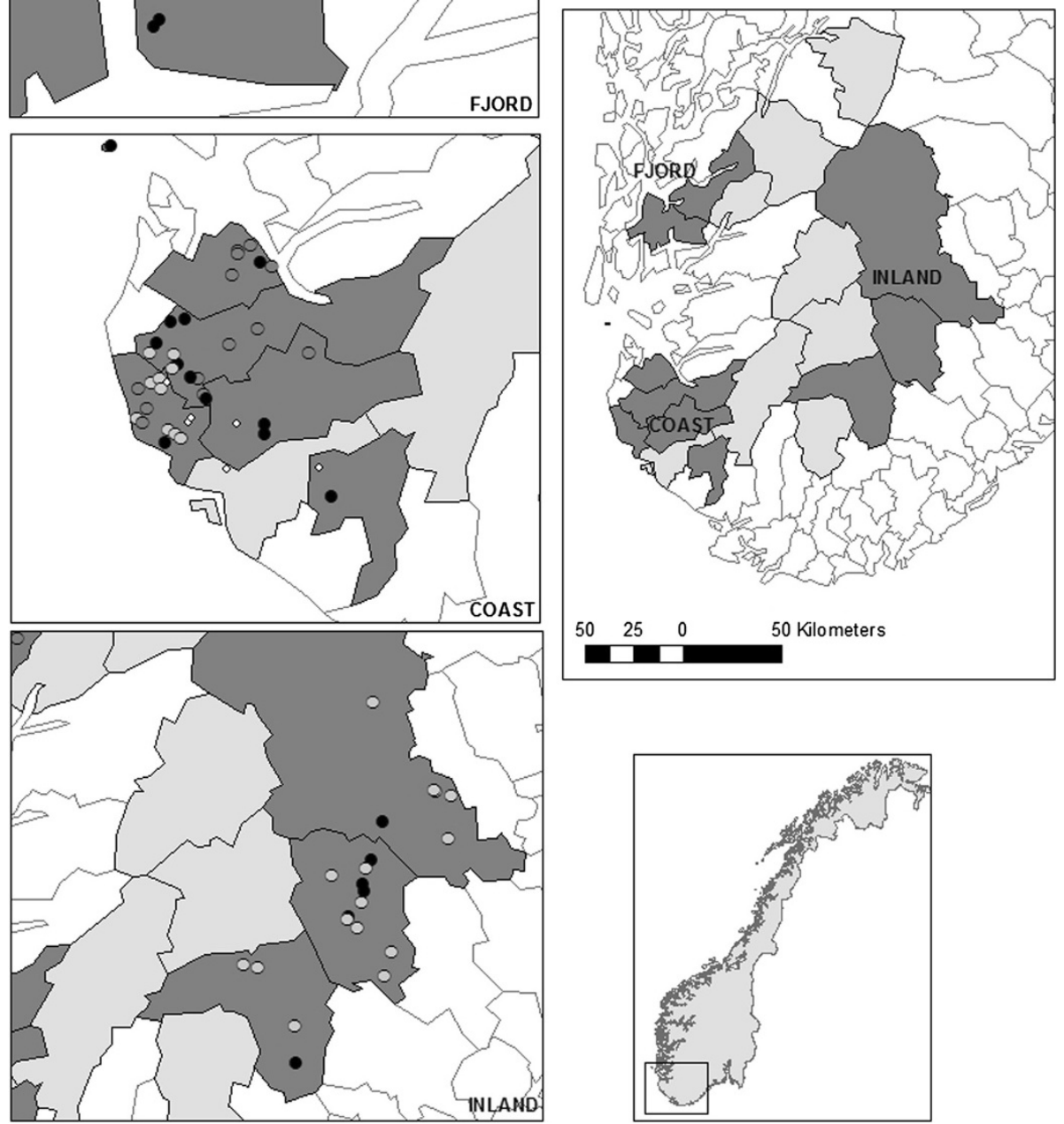

Figure 1 Geographic distribution of farms which were positive and negative for antibodies against $A$. phagocytophilum during timespan 1, timespan 2 and timespan 3 in the three regions (INLAND, COAST and FJORD). A positive farm is defined as a farm with one or more positive samples. A negative farm has no positive samples.

variation (as assessed by the AIC value), were the density of farms, relative humidity from OctoberMarch, yearly number of days with black frost, precipitations in May, duration of snow cover and abundance of red deer. The model predicts the observed farm prevalence very well (Figure 3). The AUC of the resulting model was 0.85 .

\section{At farm/infield}

The mean patch area of bush encroachment, density of livestock farms, abundance of red deer, number of days per year with day-to-day fluctuation in ground surface temperature (GST) $>5^{\circ} \mathrm{C}$, number of days with snow depth of $\leq 2 \mathrm{~cm}$ (SnoStartDays), standard deviation of mean air temperature in April and relative humidity 
Table 2 Changes in the prevalence of antibodies against A. phagocytophilum in sheep and farms

\begin{tabular}{|c|c|c|c|c|c|c|}
\hline District & Timespan & Farms tested $(n)$ & Sheep tested (n) & Positive sheep (n) & $\begin{array}{r}\text { Proportion positive } \\
\text { sheep [ } 95 \% \mathrm{Cl}]^{*}\end{array}$ & Mean farm prevalence $[90 \%$ range $]$ \\
\hline \multirow[t]{3}{*}{ INLAND } & 1 & 6 & 379 & 139 & $0.37[0.32-0.42]$ & $0.33[0.18-0.46]$ \\
\hline & 2 & 0 & 0 & n.a & n.a & n.a \\
\hline & 3 & 16 & 436 & 124 & $0.28[0.24-0.33]$ & $0.26[0.06-0.52]$ \\
\hline \multirow[t]{3}{*}{ COAST } & 1 & 12 & 520 & 252 & $0.48[0.44-0.53]$ & $0.59[0.34-0.92]$ \\
\hline & 2 & 20 & 403 & 117 & $0.29[0.26-0.35]$ & $0.39[0.00-1.00]$ \\
\hline & 3 & 12 & 339 & 210 & $0.62[0.57-0.67]$ & $0.61[0.13-1.00]$ \\
\hline \multirow[t]{3}{*}{ FJORD } & 1 & 6 & 240 & 151 & $0.63[0.56-0.69]$ & $0.72[0.14-1.00]$ \\
\hline & 2 & 9 & 326 & 249 & $0.76[0.71-0.81]$ & $0.78[0.47-1.00]$ \\
\hline & 3 & 11 & 320 & 301 & $0.94[0.91-0.96]$ & $0.94[0.80-1.00]$ \\
\hline
\end{tabular}

In the 3 study regions during three different timespans: timespan 1; 1978-1989, timespan 2; 1990 - 1999; timespan 3: 2000-2008. ${ }^{*}$ Confidence intervals obtained from assuming that the positive sheep are independent and following a binomial probability distribution.

during October-March were positively associated with the outcome. Of these variables, the highest impacts on the probability of a positive outcome were found by one unit increase in red deer abundance, SnoStartDays, and relative humidity during October-March (Table 3). The numbers of days in June with day-to-day increase in GST of $>5^{\circ} \mathrm{C}$ was negatively associated with the outcome. The amount of precipitation in May had a positive significant association with increased prevalence of TBF in sheep at lower values, and a negative relationship at higher values (>90 mm). An increase by 1 standard deviation from the mean amount of May precipitation (from $93 \mathrm{~mm}$ to $113 \mathrm{~mm}$ ) decreased the probability of a positive outcome by 0.6 (95\% CI: $0.4,0.9)$.

\section{At rough grazing}

The total area of bush encroachment and the number of days with black frost during the year were positively associated with the outcome. The probability of a positive outcome was approximately 2.5 times higher for the three bush encroachment categories with more bush encroachment than the lowest category defined by the first quartile of the variable "Area shrubi". An increase by one unit in the black frost variable increased the probability of

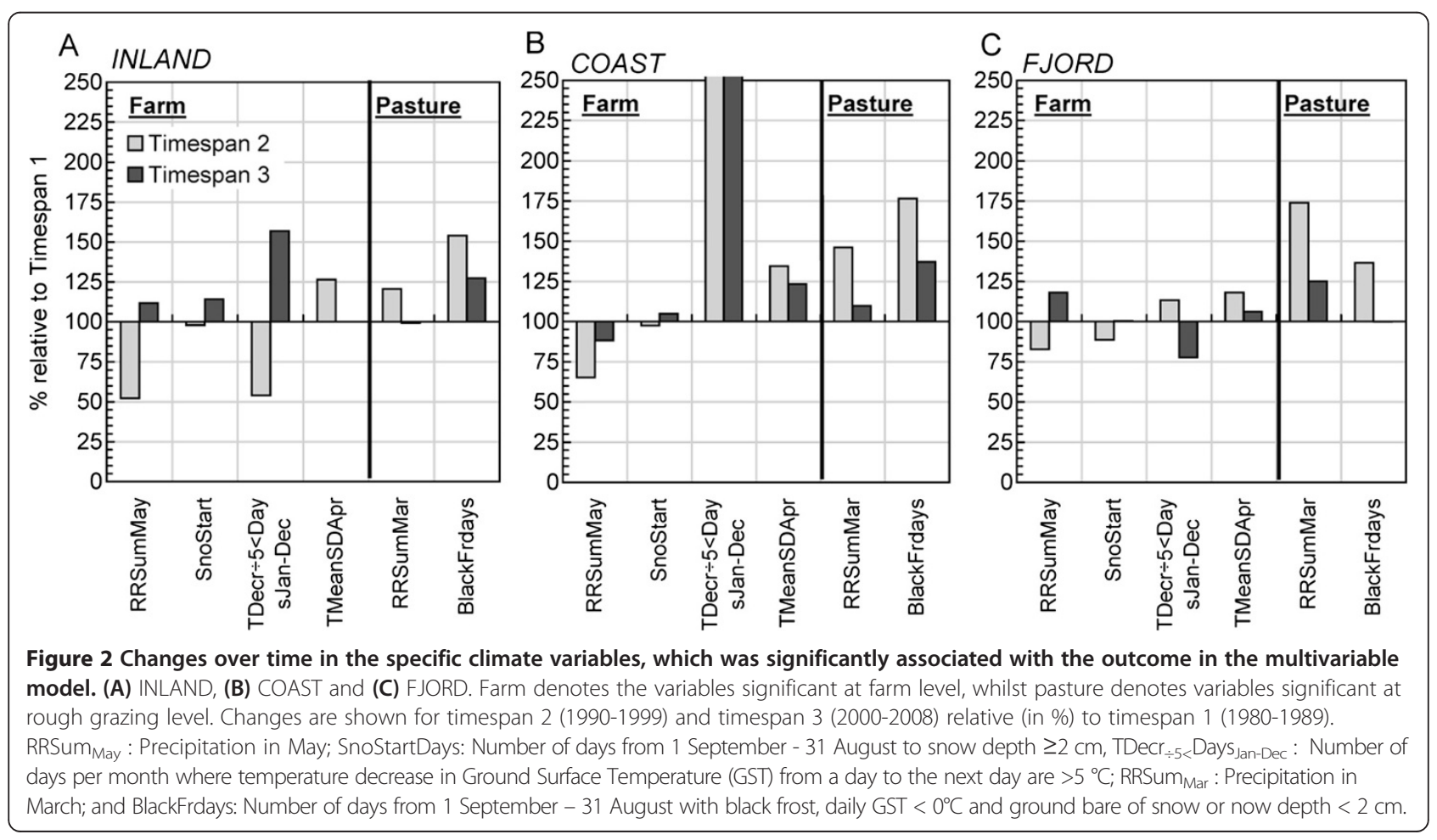


Table 3 The output (parameter estimates, standard errors and $p$-values) of the mixed effect logistic regression (see Table 1 for definitions)

\begin{tabular}{|c|c|c|c|c|c|}
\hline Variable & Estimate & $\begin{array}{l}\text { Std. } \\
\text { error }\end{array}$ & $\begin{array}{l}\text { Exp } \\
\text { (est) }\end{array}$ & P-value & $\Delta \mathrm{AIC}$ \\
\hline Intercept & 2.30 & 0.84 & & 0.006 & \\
\hline Area shrubi 1 vs. $0^{*}$ & 1.05 & 0.27 & 2.86 & $<0.001$ & \\
\hline Area shrubi 2 vs. $0^{*}$ & 0.85 & 0.23 & 2.35 & $<0.001$ & 14 \\
\hline Area shrubi 3 vs. $0^{*}$ & 0.79 & 0.23 & 2.21 & $<0.001$ & \\
\hline Meanarea_p & 0.45 & 0.12 & \multirow{2}{*}{1.40} & $<0.001$ & \multirow{2}{*}{9} \\
\hline Meanarea_p $p^{2}$ & -0.11 & 0.03 & & $<0.001$ & \\
\hline $\mathrm{RH}_{\text {mean }}$ Oct-Mar & 1.21 & 0.13 & 3.34 & $<0.001$ & 88 \\
\hline BlackFrdays & 0.92 & 0.16 & 2.50 & $<0.001$ & 55 \\
\hline SnoStartDays & 1.17 & 0.20 & 3.23 & $<0.001$ & 34 \\
\hline NuFarms & 2.67 & 0.31 & \multirow{2}{*}{2.27} & $<0.001$ & \multirow{2}{*}{94} \\
\hline NuFarms ${ }^{2}$ & -1.85 & 0.21 & & $<0.001$ & \\
\hline Red deer & 1.28 & 0.22 & 3.59 & $<0.001$ & 29 \\
\hline Pasture & -1.36 & 0.30 & 0.25 & $<0.001$ & 18 \\
\hline RRSum $_{\text {May }}$ & -0.18 & 0.15 & \multirow{2}{*}{0.59} & 0.224 & \multirow{2}{*}{46} \\
\hline RRSum $_{\text {May }}^{2}$ & -0.35 & 0.06 & & $<0.001$ & \\
\hline RRSum $_{\text {Mar }}$ & -0.40 & 0.14 & 0.67 & 0.004 & 6 \\
\hline Tlncr $+5<$ Days Jun & -1.11 & 0.21 & \multirow{2}{*}{0.40} & $<0.001$ & \multirow{2}{*}{27} \\
\hline Tlncr $+5<$ Days $_{\text {Jun }}^{2}$ & 0.19 & 0.04 & & $<0.001$ & \\
\hline TMeanSD $_{A p r}$ & 0.43 & 0.22 & \multirow{2}{*}{1.93} & 0.047 & \multirow{2}{*}{5} \\
\hline $\mathrm{TMeanSD}_{\mathrm{Apr}}^{2}$ & 0.22 & 0.08 & & 0.004 & \\
\hline TDecr $\div 5<$ Days Jan - Dec & 0.22 & 0.10 & 1.25 & 0.035 & 2 \\
\hline
\end{tabular}

$\triangle \mathrm{AIC}$ denotes the change in AIC level obtained if excluding the relevant variable from the selected model. The continuous variables are scaled (before taking polynomials) to mean zero and variance one. The factor by which the odds of positive outcome are increased for each one-unit change in the variables are represented by the computed exp (estimates). For the polynomials the odds ratio is calculated only for an increase of one standard deviation from mean. ICC (Intraclass correlation; ratio of the variance between subjects over the total variance) for municipality was 0.33 and ICC for timespan was 0.36 . The "Area shrubi" variable was categorized (in 4 equal parts defined by quartiles) to capture the nonlinear relationship (at logit-scale) with the outcome. The variables Area shrubi, BlackFrDays and RRSumMar represent the rough grazing level.

a positive outcome by 2.5 times (95\% CI: 1.8, 3.4). The amount of precipitation in March was negatively associated with the outcome.

\section{Discussion}

Understanding the response of populations to environmental change requires detailed spatial and temporal data, and also consideration of the variability in conditions and of non-climatic factors along with the climate [34,35]. Many disease distribution models use means, ignoring fluctuations, and will probably not be able to predict the diversity of animal responses. Incorporation of non-climatic factors, such as biotic interactions, is especially important [36,37]. Our models covered climate and its variability, habitat alteration, and changes in host animal populations, agricultural practices and demography through three decades.

\section{Distribution of Ixodes ricinus}

The upslope shift of $I$. ricinus is even greater than documented previously [18], with a positive INLAND farm at 748 masl. Sheep serum positive for $A$. phagocytophilum in INLAND and parts of the COAST districts (Figure 1) in the early 1980's did not correspond with published distribution maps [26,27]. This might be caused by different data resolution [18].

FJORD had higher numbers of positive sheep compared to COAST, probably indicating that ticks were relatively more abundant in FJORD. The number of positive sheep increased in FJORD, and more recently in COAST, indicating an increased sheep-tick exposure over time. It might also indicate that as A. phagocytophilum, which causes persistent infections in sheep [38] gets established in an area, there will be more reservoir hosts for more ticks to be infected and spread the disease. It is more difficult to explain why in INLAND the number of positive sheep decreased over time. One possible explanation is that a reduction in the number of sheep farms in INLAND might have resulted in less contact between herds during summertime, possibly lowering the infection risk for sheep coming from areas where ticks are uncommon. In addition, climate change was less pronounced and the INLAND-farms/rough grazing were at higher altitudes, however, INLAND had the most pronounced degree of bush encroachment. The prevalence of $A$. phagocytophilum in sheep could also be influenced by the tick infection prevalence rate, the tick life cycle and the density of sheep, cattle and wildlife hosts. The specific strains of $A$. phagocytophilum circulating might also be of importance as some may not be infective to sheep.

As whole cell bacterial antigens were used, it is expected that the method will detect antibodies against all strains of A. phagocytophilum that infect sheep. However, as not all strains of $A$. phagocytophilum infect sheep, the results could underestimate the distribution of ticks. Using prevalence of $A$. phagocytophilum in sheep as a proxy to establish temporal changes in the range and density of ticks could potentially miss tick populations which do not harbour A. phagocytophilum or strains of the organism that do not infect sheep, and thus underestimate the range and density of tick populations.

One possible weakness of the present study is that it did not investigate the prevalence of $A$. phagocytophilum in $I$. ricinus during the study period. There is, however, a problem of inference since prevalence in questing and feeding ticks can differ vastly; e.g. a Belgian study found only an $A$. phagocytophilum prevalence of $3 \%$ in questing ticks, whilst a prevalence of $21.7 \%$ in feeding ticks 


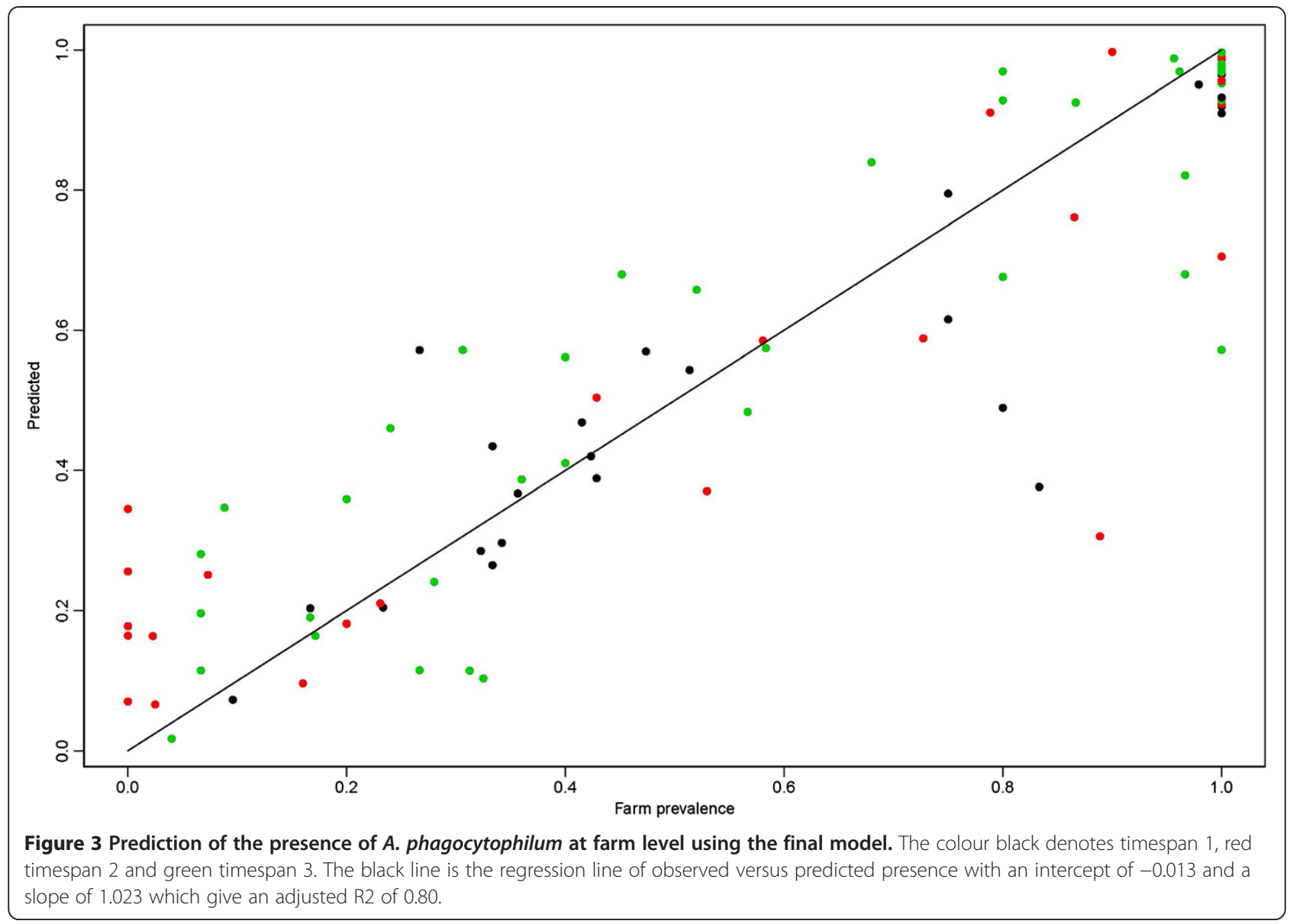

[39]. Thus low prevalence in questing ticks might not be indicative of infection rates.

\section{Climatic factors}

Climate variability - tick population and $\mathrm{A}$. phagocytophilum transmission

The data indicates that there was a significant increase in the frequency of monthly drops in temperature with time in COAST and INLAND during the latter timespan (Figure 2). Climate change may increase temperature variability [8]. Raffel et al. [33] concluded that an increase in the severity of unpredictable drops in temperature might be relevant to disease transmission. Ectotherms generally adapt to temperature variations by a left-skewed asymmetric response [40] resulting in a non-linear relationship between body temperature and fitness. In addition, temperate ectotherms, like those living in Norway, have a lower optimal temperature relative to the species maximum temperature, and display a greater asymmetry compared to Mediterranean and tropical ectotherms. Furthermore, studies on the malaria vector (Anopheles stephensi) and pathogen (Plasmodium chabaudi) have revealed that fluctuations around the lower temperatures $\left(16-18^{\circ} \mathrm{C}\right)$ speed up intensity of pathogen transmission, whilst fluctuations around higher temperatures $\left(24-26^{\circ} \mathrm{C}\right)$ might slow it down [41]. Such fluctuations probably also affect the stress resistance of the vector, and the contraction and multiplication of the infectious agents within the vector [41,42]. Paaijmans et al. [41] have shown that the mosquito and parasite are influenced by the extent of daily temperature variations and suggest the need to consider this for other ectotherms. This might explain why large fluctuations in temperature were positively associated with the presence of Anaplasma-infected ticks. In a theoretical model, temperature variability was found to strongly affect the time at which I. ricinus cohorts emerged [43].

\section{Duration of snow cover - tick population}

Climatic changes during the last 30-40 years in Southern Norway have had the clearest impact in winter [44]. Warmer winters with less snow and increase in spring temperatures are accompanied by earlier spring snow melt and bare ground, which causes rapid spring warming and greater drying of soils and vegetation [45]. The absence/presence of snow cover, rather than the length of the growth season, was significant for tick distribution. As long as the snow is absent ticks can still quest, given that the temperature during some period of the 
day is high enough, even though the growth season has ended. The prominent coastal distribution of I. ricinus in Norway is better explained by the length of the period without snow than the length of the growth period. James et al. [46] also found that the length of the growth season was not significant when modeling environmental determinants of I. ricinus in Scotland. However, a study on the distribution of I. ricinus in Sweden regards the length of the growth season as the best predictor for tick distribution, but this study also described I. ricinus as consistently present when the period of snow cover was $\leq 125 \mathrm{~d} /$ year and as consistently absent with a snow cover $\geq 175 \mathrm{~d} /$ year [47]. The importance of relative humidity during the winter months probably results from the impact on ticks that are not protected by snow cover. Snow cover affects the survival of ticks during winter [48], as it increases ground surface temperatures [49] and ensures stable and high relative humidity in the air. In places with little or no snow the ticks are not protected, and the absence of snow together with low relative humidity will probably kill the ticks. The significance of number of days with black frost in the rough grazing areas might reflect that absence of snow cover during the winter is far more crucial for I. ricinus than the actual exposure temperature. Precipitation in March serves as an indicator of the duration of snow cover in INLAND and areas of higher elevation in COAST and FJORD, as the precipitation consists mostly of snow. An accumulation of snow can delay the start of spring in the rough grazing areas, rendering the habitats less favourable for ticks and their hosts.

\section{Spring temperature - tick population}

Increased temperature fluctuations during April (Figure 2), are often linked to the presence of persisting highpressure systems producing sunny, calm weather with gradually increasing air temperatures. April is normally the month with the highest degree of temperature rise, and marks the transition from winter to spring. The IPCC reports that there is very high confidence that there is an earlier start to spring [50], and since 1900 the temperature increase in Norway has been greatest in spring [44]. An early exit from diapause can be critical for interstadial development and thus the presence and abundance of ticks [51]. Dobson et al. [51] suggested that developmental diapause exit for I. ricinus is around 1st of April in England - and that April-July is a critical phase for the tick inter-stadial development. Additionally, the effects of climate conditions on winter/spring survival of important tick hosts need to be considered, as was observed for white-footed mice (Peromyscus leucopus), in Canada, an important tick larval host [52]. It is possible that persisting high- pressure systems also have an indirect effect through increased survival of small animal hosts for the ticks.

\section{Precipitation in May - tick population}

The effect of precipitation in May (Figure 2) had a nonlinear effect. There was a positive relationship with low precipitation values, and a negative one for high precipitations (> $90 \mathrm{~mm}$ per month). Since the 1990s, precipitations have increased substantially in May [44] (Figure 2). A recent study by Dyrrdal et al. [53] showed that the frequency of moderate to strong precipitation events has increased in most parts of Norway since 1957, particularly in wet regions. The intensity of strong precipitation events has also showed a general increase. IPCC reports that climate change very likely has increased the frequency of observed heavy precipitation events [50].

Studies on I. scapularis from Ontario in Canada [54] and I. ricinus at several British sites [51,55], climatically similar to some places in Norway, indicate that egg deposition take place during late April - May. The climatic factors during the month of egg deposition will probably be critical for the distribution of ticks, as there would not be sustainable tick population if the eggs do not survive and hatch. The effect of flooding upon the dog ticks (Rhipicephalus sanguineus and Haemaphysalis leachi leachi) shows that flooding affected oviposition, reduced the number of eggs laid and the percentage of hatchability [56]. It has been suggested that heavy rain silts up the egg masses [57]. Other studies have shown that light-to-moderate rainfall is favourable for oviposition, whilst excessive rainfall reduces oviposition and tick distribution $[58,59]$.

Firm interpretation of significant climate variables is challenging, but these results highlight the role of variability and directions for future research on the role of climate.

\section{Land cover and bush encroachment- tick population and A. phagocytophilum transmission}

In this study we focused on one specific aspect of vegetation change, bush encroachment. This change may be related to a more favorable environment for ticks [60-62], especially in areas where it connects to other landscape types $[60,63]$. Trees and bushes probably provide a more stable and humid microhabitat, thereby potentially enhancing tick survival [60]. At farm- level, beyond the direct effects of increasing areas more suitable for ticks and some hosts, the size of patch would relate to the presence of ecotones, that is, interfaces between bushy or woody vegetation and grasslands, with more possibilities for interaction between suitable areas and susceptible sheep.

Woodlands are the natural habitat for I. ricinus [63] as they provide a favorable environment and a diversity of 
hosts. Small mammals and wild cervids circulate between woodlands, ecotones and pasture areas and this movement of animals affects the distribution of $I$. ricinus [64]. In rough grazing, the exact area used by sheep is impossible to outline, and the characterization of those areas may be more indicative, resulting in more generic variables, such as area, being significant. Bush encroachment of open fields in Norway is linked to decreasing numbers of farms, changed forestry practices, change of agricultural use and climate change [65]. Forest regrowth is likely to ultimately replace bush in encroached areas. Regrowth after abandonment or reduced use and climate change are concurrent, and hard to separate. At this stage, land use might have a greater impact on forest regrowth than climate change in Norway $[65,66]$. Rough grazing is considered the main restricting factor for forest re-growth [67]. In Sweden and Latvia, an increase in the prevalence of tick-borne disease has been associated with abandonment of fields and pastures and with the expansion of woodland $[68,69]$.

\section{Domestic animal hosts - tick population and \\ A. phagocytophilum transmission}

The significance of the number of livestock farms in the municipality could be related to the fact that the presence of more farms will provide more ruminants and thus major tick hosts. This would be in contrast to the widespread belief that reintroduction of sheep and cattle to an area will alleviate the tick burden through the effect of grazing on the vegetation [70,71]. However, densities in Norway may be insufficient to affect tick habitat suitability as was observed elsewhere. A higher number of farms might be associated with increased contact between herds on rough grazing. Herds from tick-infested areas will then seed ticks into the rough grazing pasture areas, possibly causing increased tick exposure for other herds utilizing the same areas. Anthropogenic activities such as farming have also the potential to change the availability and density of hosts and vectors, and thus indirectly influence the spread and persistence of infectious pathogens within an ecosystem [72-74].

\section{Cervid populations - tick population and}

\section{A. phagocytophilum transmission}

In the multivariable analyses red deer was the only cervid that had a significantly positive association with the outcome. Roe deer and moose were not associated with the outcome. The role of these species might be different depending on the A. phagocytophilum strain.

The strains infecting roe deer belongs to a different ankA gene cluster than those infecting red deer, sheep, European bison and cows, and roe deer might not be relevant reservoirs for granulocytic anaplasmosis in humans and domestic animals [75]. Red deer has been reported as hosts for $16 \mathrm{~S}$ rDNA variants of $A$. phagocytophilum, known to cause TBF in sheep [76]. This might provide an explanation as to why red deer, and not roe deer, were significant. However, msp4 genotyping performed indicated a clustering of wild ruminant strains distinct from sheep variants [76]. There are several distinct A. phagocytophilum $16 \mathrm{~S}$ rDNA and msp4 gene variants circulating in sheep and wildlife in Norway [77], six $16 \mathrm{~S}$ rDNA and $24 \mathrm{msp} 4$ variants have been reported [76,77]. The transmission cycle of A. phagocytophilum in Europe is not completely understood and we do not know the specific role of the different tick host species in the transmission cycle [75]. Infection risk for $A$. phagocytophilum over the years might thus potentially be related to changes in one of the reservoir species.

Cervid species are regarded as key hosts to ticks $[78,79]$. High population densities of cervids are expected to be associated with efficient host finding and adequate nutrition for ticks. However, cervids may also affect tick abundance through the effect of grazing on vegetation. Results from studies on the influence of roe deer on tick abundance are conflicting [80-85] even though positive associations between roe deer and tick abundance have been reported [86-88]. Evidence points towards a far more complex relationship between deer and tick density, where for instance density of deer above threshold values might have little effect on tick abundance $[89,90]$ or a decoupling of stage-specific tick abundances can occur [81]. The relationship between deer abundance and tick birth rate is probably difficult to predict because ticks can aggregate on fewer deer or alternate hosts in response to abundance declines.

Hunting data at the municipality level was used as a proxy for the total population of cervids. The number of bagged cervids is reported to reflect the overall size of the total population [91], although some urge caution in using wildlife bag data since differences in spatiotemporal patterns between bag data and population size have been detected [92].

\section{Conclusion}

Tick distribution and tick bite exposure are associated with a complex combination of climatic and environmental factors, including those related to human activities, which operate at diverse spatial and temporal scale. This multifactorial interdisciplinary study contributes to a more comprehensive understanding of the intricacies and interactions of the drivers of shifts in I. ricinus distribution, and represents an advance by considering biotic and abiotic factors simultaneously. The study also integrates seasonality, short-term temperature dynamics and possible climatic threshold effects, which appeared essential even though interpretation remains challenging. Expected climate changes accentuate the importance 
of our finding, and the need for considering climate variability effects upon ticks and tick-borne pathogens. The relative importance of the different factors studied here might change as the global environment continues to change, including the respective role of abiotic/biotic factors and those related to human land use.

\section{Additional file}

\section{Additional file 1: Supplementary material.}

\section{Competing interests}

The authors declare that they have no competing interests.

\section{Authors' contributions}

The study was planned in collaboration between the authors with SJ as a project leader. SJ did the majority of manuscript writing, but all co-authors contributed with improvements and discussions. SJ, HV and ABK carried out the data analysis. All authors read and approved the final version of the manuscript.

\section{Acknowledgements}

This study was funded by seed money from the Norwegian Veterinary Institute (NVI). Sincere thanks to Richard Ostfeld (Cary Institute of Ecosystem Studies, USA) for discussions around the paper, valuable advice upon modeling and for helpful review and comments on the manuscript. Thanks to Matthew Thomas (Center for Infectious Disease Dynamics and Department of Entomology, Penn State, USA) for guidance in the complex field of temperature fluctuations and transmission. Gratitude to Anita Verpe Dyrrdal (The Norwegian Meteorological Institute (met.no)) who provided the gridded data on air temperature, precipitation and snow depth; Jan Erik Haugen (met.no) and Hilde Haakenstad (met.no) which provided the hindcast data; and Hans Olav Hygen (met.no) which made a data aggregation of the climate data to provide the climate variables used in further analyses. Special thanks to farmers and people employed at the agricultural offices in the municipalities which helped tracing historical information about grazing areas for the sheep. Thanks to Preben Ottesen (Norwegian Public Health Institute) and Petter Hopp (NVI) for discussions around the study, Bruce David for language help with the paper, John Odden and Henrik Brøseth at Norwegian Institute for Nature Research for providing the number of bagged roe deer per municipality, Attila Tarpai (NVI) for GIS assistance, and Gry Grøneng (NVI) for generating sample overview.

\section{Author details}

${ }^{1}$ Norwegian Veterinary Institute, Ullevålsveien 68, P.O.Box 750, Sentrum 0106, Oslo, Norway. ${ }^{2}$ Georges Lemaître Centre for Earth and Climate Research, Earth \& Life Institute, Université Catholique de Louvain, Place Louis Pasteur 3, B1348, Louvain-la-Neuve, Belgium. ${ }^{3}$ Centre for Ecological and Evolutionary Synthesis (CEES), Department of Bioscience, University of Oslo, P.O.Box 1066, Blindern 0316, Oslo, Norway. ${ }^{4}$ The Norwegian Meteorological Institute, Research and Development Department, Division for Model and Climate Analysis, P.O.Box 43, Blindern 0313, Oslo, Norway. ${ }^{5}$ Department of Informatics, University of Oslo, P.O.Box 1080, Blindern 0316, Oslo, Norway. ${ }^{6}$ Department of Infection Biology, Institute of Infection \& Global Health, University of Liverpool, Leahurst Campus, Chester High Road, Neston, Wirral CH64 7TE, UK. ${ }^{7}$ Northern Research Institute, P.O. Box 6434, Forskningsparken 9294, Tromsø, Norway. ${ }^{8}$ Norwegian School of Veterinary Science, Ullevålsveien 72, P.O.Box 8146Dep., 0033, Oslo, Norway. ${ }^{9}$ Department of Geosciences, University of Oslo, P.O.Box 1066, Blindern 0316, Oslo, Norway.

Received: 7 November 2013 Accepted: 31 December 2013 Published: 8 January 2014

\section{References}

1. Randolph SE: Tick-borne disease systems emerge from the shadows: the beauty lies in molecular detail, the message in epidemiology. Parasitology 2009, 136:1403-1413.

2. Gray JS, Dautel H, Estrada-Pena A, Kahl O, Lindgren E: Effects of climate change on ticks and tick-borne diseases in europe. Interdiscip Perspect Infect Dis 2009, 2009:593232.

3. Anderson BJ, Akcakaya HR, Araujo MB, Fordham DA, Martinez-Meyer E, Thuiller W, Brook BW: Dynamics of range margins for metapopulations under climate change. Proc R SOC B Biol Sci 2009, 276:1415-1420.

4. Randolph SE: Tick ecology: processes and patterns behind the epidemiological risk posed by ixodid ticks as vectors. Parasitology 2004, 129(Suppl):S37-S65.

5. Macleod JAJ: The binomics of Ixodes ricinus L.,the "sheep tick" of Scotland. Parasitology 1932, 24:382-400

6. Perret $J$, Rais O, Gern L: Influence of climate on the proportion of Ixodes ricinus nymphs and adults questing in a tick population. $J$ Med Entomol 2004, 41:361-365.

7. Macleod JAJ: Ixodes ricinus in relation to its physical environment. IV. An analysis of the ecological complexes controlling distribution and activities. Parasitology 1936, 28:295-315.

8. Field CB, Barros V, Stocker TF, Quin D, Dokken DJ, Ebi KL, et al: United Kingdom and New York, NY, USA: Cambridge university press; 2012.

9. Randolph SE: Ticks and tick-borne disease systems in space and from space. Adv Parasitol 2000, 47:217-243

10. Rogers DJ, Randolph SE, Snow RW, Hay SI: Satellite imagery in the study and forecast of malaria. Nature 2002, 415:710-715.

11. Randolph S: The impact of tick ecology on pathogen transmission dynamics. In Ticks: Biology, Disease and Control. Edited by Bowman AS, Nuttall PA. Cambridge, UK: Cambridge University Press; 2008:40-72.

12. Altizer $S$, Dobson A, Hosseini $P$, Hudson P, Pascual M, Rohani P: Seasonality and the dynamics of infectious diseases. Ecol Lett 2006, 9:467-484.

13. Kovats RS, Campbell-Lendrum DH, McMichael AJ, Woodward A, Cox JS: Early effects of climate change: do they include changes in vector-borne disease? Phil Trans R Soc Lond B-Biol Sci 2001, 356:1057-1068.

14. Dobson ADM, Randolph SE: Modelling the effects of recent changes in climate, host density and acaricide treatments on population dynamics of Ixodes ricinus in the UK. J Appl Ecology 2011, 48:1029-1037.

15. Randolph SE: Mighty theories from little acorns grow: is Lyme disease risk predictable from mast-seeding by oak trees? Trends in Ecol Evol 1998, 13:301-303

16. Medlock JM, Hansford KM, Bormane A, Derdakova M, Estrada-Pena A, George JC, Golovljova I, Jaenson TGT, Jensen JK, Jensen PM, et al: Driving forces for changes in geographical distribution of Ixodes ricinus ticks in Europe. Parasit Vectors 2013, 6:1.

17. Randolph SE: Evidence that climate change has caused 'emergence' of tick-borne diseases in Europe? Int J Parasitol 2004, 293(Suppl 37):5-15.

18. Jore S, Viljugrein H, Hofshagen M, Brun-Hansen H, Kristoffersen A, Nygard K, Brun E, Ottesen P, Saevik B, Ytrehus B: Multi-source analysis reveals latitudinal and altitudinal shifts in range of Ixodes ricinus at its northern distribution limit. Parasit Vectors 2011, 4:84.

19. Stuen S, Bergstrom K: Serological investigation of granulocytic Ehrlichia infection in sheep in Norway. Acta Vet Scand 2001, 42:331-338.

20. Woldehiwet Z: The natural history of Anaplasma phagocytophilum. Vet Parasitol 2010, 167:108-122.

21. Cochez C, Ducoffre G, Vandenvelde C, Luyasu V, Heyman P: Human anaplasmosis in Belgium: a 10-year seroepidemiological study. Ticks Tick Borne Dis 2011, 2:156-159.

22. Kocan KM, Busby AT, Allison RW, Breshears MA, Coburn L, Galindo RC, Ayllon N, Blouin EF, de la Fuente J: Sheep experimentally infected with a human isolate of Anaplasma phagocytophilum serve as a host for infection of Ixodes scapularis ticks. Ticks Tick Borne Dis 2012, 3:147-153.

23. Woldehiwet $Z$ : Anaplasma phagocytophilum in ruminants in Europe. Ann N Y Acad Sci 2006, 1078:446-460.

24. Coleman PG, Perry BD, Woolhouse ME: Endemic stability-a veterinary idea applied to human public health. Lancet 2001, 357:1284-1286.

25. Van den Bossche P, Coetzer JA: Climate change and animal health in Africa. Review Scientif Techn 2008, 27:551-562.

26. Mehl R: The distribution and host relations of Norwegian ticks (Acari, Ixodides). Fauna norvegica Series B 1983, 30:46-51. 
27. Tambs-Lyche $\mathrm{H}$ : Ixodes ricinus og piroplasmosen i Norge (Meddelelse fra Bergens Museums zoologiske avdeling). Norsk veterinærtidsskrift 1943, 55:337-542.

28. Woldehiwet Z, Horrocks BK: Antigenicity of ovine strains of Anaplasma phagocytophilum grown in tick cells and ovine granulocytes. J Comp Pathol 2005, 132:322-328.

29. Woldehiwet Z, Yavari C: Evaluation of an indirect enzyme-linked immunosorbent assay (ELISA) for the detection of antibodies against Anaplasma phagocytophilum in sheep. J Comp Pathol 2012, 146:116-121.

30. R: A language and environment for statistical computing; 2011. http:/www.r-project.org.

31. Wood SN: Generalized additive models:an introduction with R. London: Chapman \& Hall, CRC; 2006.

32. Burnham KP, Anderson DR: Multimodel Inference:understanding AIC and BIC in model selection. Sociol Methods Research 2004, 33:261-304.

33. Mason SJ, Graham NE: Areas beneath the relative operating characteristics (ROC) and relative operating levels (ROL) curves: Statistical significance and interpretation. Quarterly J Royal Meteorol Soc 2002, 128:2145-2166.

34. Hijmans RJ, Graham CH: The ability of climate envelope models to predict the effect of climate change on species distributions. Glob Change Biology 2006, 12:2272-2281.

35. Raffel TR, Romansic JM, Halstead NT, McMahon TA, Venesky MD, Rohr JR: Disease and thermal acclimation in a more variable and unpredictable climate. Nat Clim Chang 2012, 3:146-151.

36. Araujo MB, Luoto $M$ : The importance of biotic interactions for modelling species distributions under climate change. Glob Ecol Biogeogr 2007, 16:743-753.

37. Jaeschke A, Bittner $T$, Jentsch A, Reineking B, Schlumprecht $H$, Beierkuhnlein C: Biotic interactions in the face of climate change: a comparison of three modelling approaches. PLOS ONE 2012, 7:e51472.

38. Thomas RJ, Birtles RJ, Radford AD, Woldehiwet Z: Recurrent bacteraemia in sheep infected persistently with anaplasma phagocytophilum. J Comp Pathol 2012, 147:360-367.

39. Lempereur L, Lebrun M, Cuvelier P, Sepult G, Caron Y, Saegerman C, Shiels B, Losson B: Longitudinal field study on bovine Babesia spp. and Anaplasma phagocytophilum infections during a grazing season in Belgium. Parasitol Res 2012, 110:1525-1530.

40. Deutsch CA, Tewksbury JJ, Huey RB, Sheldon KS, Ghalambor CK, Haak DC, Martin PR: Impacts of climate warming on terrestrial ectotherms across latitude. Proc Natl Acad Sci USA 2008, 105:6668-6672.

41. Paaijmans KP, Blanford S, Bell AS, Blanford Jl, Read AF, Thomas MB Influence of climate on malaria transmission depends on daily temperature variation. Proc Natl Acad Sci USA 2010, 107:15135-15139.

42. Folguera G, Bastias DA, Caers J, Rojas JM, Piulachs MD, Belles X, Bozinovic F: An experimental test of the role of environmental temperature variability on ectotherm molecular, physiological and life-history traits: Implications for global warming. Comp Biochem Physiol A Mol Integr Physiol 2011, 159:242-246.

43. Hancock PA, Brackley R, Palmer SCF: Modelling the effect of temperature variation on the seasonal dynamics of Ixodes ricinus tick populations. Int J Parasitol 2011, 41:513-522.

44. Hanssen-Bauer I, Drange H, Førland EJ, Roald LA, Børsheim KY, Hisdal H, Lawrence D, Nesje A, Sandven S, Sorteberg A, Sundby S, Vasskogog K, ESPON 2013 244, Adlandsvik B: Klima i Norge 2100. Bakgrunnsmateriale til NOU Klimatilplassing, Norsk klimasenter, September 2009. Oslo; 2009.

45. Westerling AL, Hidalgo HG, Cayan DR, Swetnam TW: Warming and earlier spring increase western US forest wildfire activity. Science 2006, 313:940-943.

46. James MC, Bowman AS, Forbes KJ, Lewis F, McLeod JE, Gilbert L: Environmental determinants of Ixodes ricinus ticks and the incidence of Borrelia burgdorferi sensu lato, the agent of Lyme borreliosis, in Scotland. Parasitology 2013, 140:237-246.

47. Jaenson TG, Eisen L, Comstedt P, Mejlon HA, Lindgren E, Bergstrom S, Olsen B: Risk indicators for the tick Ixodes ricinus and Borrelia burgdorferi sensu lato in Sweden. Med Vet Entomol 2009, 23:226-237.

48. Gray DM, Male DH: Snow and climate. Pergamon, Toronto: Handbook of snow; 1981.

49. Isaksen K, Odegard RS, Etzelmuller B, Hilbich C, Hauck C, Farbrot H, Eiken T, Hygen HO, Hipp TF: Degrading mountain permafrost in Southern Norway: spatial and temporal variability of mean ground temperatures, 1999-2009. Permafrost Periglac Process 2011, 22:361-377.
50. Trenberth KE, Jones PD, Ambenje P, Bojariu R, Easterling D, Klein Tank A, Parker D, Rahimzadeh F, Renwick JA, Rusticucc M, Soden B, Zhai P, Solomon S, Qin D, Manning M, Chen Z, Marquis M, Averyt KB, Tignor M, Miller HL: Observations: Surface and Atmospheric Climate Change. In Climate Change 2007: The Physical Science Basis. Contribution of Working Group I to the Fourth Assessment Report of the Intergovernmental Panel on Climate Change. Cambridge, United Kingdom and New York, NY, USA: Cambridge University Press; 2007.

51. Dobson ADM, Finnie TJR, Randolph SE: A modified matrix model to describe the seasonal population ecology of the European tick Ixodes ricinus. J Appl Ecol 2011, 48:1017-1028.

52. Martin N: Effects of Climate Change on the Distribution of white-footed mouse (Peromyscus leucopus), an Ecologically and Epidemiologically Important Species, PhD Thesis. University of Michigan; 2010.

53. Dyrrdal AV, Isaksen K, Hygen HO, Meyer NK: Past changes in frequency, intensity and spatial occurrence of meteorological triggering variables relevant for natural hazards in Norway. Climate Res 2012, 55:153-165.

54. Lindsay LR, Barker IK, Surgeoner GA, Mcewen SA, Gillespie TJ, Robinson JT: Survival and development of ixodes-scapularis (Acari, Ixodidae) under various climatic conditions in Ontario, Canada. J Med Entomol 1995, 32:143-152.

55. Randolph SE, Green RM, Hoodless AN, Peacey MF: An empirical quantitative framework for the seasonal population dynamics of the tick Ixodes ricinus. Int J Parasitol 2002, 32:979-989.

56. Adejinmi JO: Effect of water flooding on the oviposition capacity of engorged adult females and hatchability of eggs of dog ticks: Rhipicephalus sanguineus and Haemaphysalis leachi leachi. J Parasitol Res 2011, 2011:824162.

57. Sutherst RW: An experimental investigation into the effects of flooding on the ixodid tick Boophilus microplus. Oecologia 1971, 6:208-222.

58. Dipeolu OO: Studies on ticks of veterinary importance in Nigeria XII. Oviposition and enclosion in five species of ixodid ticks in contrasting habitats. Exp Appl Acarol 1985, 1:45-62.

59. Olwoch JM, Rautenbach CJDW, Erasmus BFN, Engelbrecht FA, Van Jaarsveld AS: Simulating tick distributions over sub-Saharan Africa: the use of observed and simulated climate surfaces. J Biogeogr 2003, 30:1221-1232.

60. Estrada-Pena A: Distribution, abundance, and habitat preferences of Ixodes ricinus (Acari : Ixodidae) in northern Spain. J Med Entomol 2001, 38:361-370.

61. Hubalek Z, Halouzka J, Juricova Z, Sikutova S, Rudolf I: Effect of forest clearing on the abundance of Ixodes ricinus ticks and the prevalence of Borrelia burgdorferi S.I. Med Vet Entomol 2006, 20:166-172.

62. Ward SE, Brown RD: A framework for incorporating the prevention of Lyme disease transmission into the landscape planning and design process. Land Urban Planning 2002, 66:91-106.

63. Tack W, Madder M, Baeten L, Vanhellemont M, Gruwez R, Verheyen K: Local habitat and landscape affect Ixodes ricinus tick abundances in forests on poor, sandy soils. Forest Ecol Manag 2012, 265:30-36.

64. Hoch T, Monnet Y, Agoulon A: Influence of host migration between woodland and pasture on the population dynamics of the tick Ixodes ricinus: a modelling approach. Ecol Modelling 2010, 221:1798-1806.

65. Bryn A, Dourojeanni $P$, Hemsing $L \varnothing, O^{\prime}$ Donell $S$ : A high resolution GIS model of potential forest expansion following land use changes in Norway. Scand J Forest Res 2012, 28:81-98.

66. Bryn A: Recent forest limit changes in south-east Norway: effects of climate change or regrowth after abandoned utilisation? Norw J Geogr 2008, 62:251-270.

67. Aune S, Hofgaard A, Soderstrom L: Contrasting climate- and land-use-driven tree encroachment patterns of subarctic tundra in northern Norway and the Kola Peninsula. Canadian J Forest Res 2011, 41:437-449.

68. Jaenson TGT, Jaenson DGE, Eisen L, Petersson E, Lindgren E: Changes in the geographical distribution and abundance of the tick Ixodes ricinus during the past 30 years in Sweden. Parasit Vectors 2012, 5:8.

69. Vanwambeke SO, Sumilo D, Bormane A, Lambin EF, Randolph SE: Landscape predictors of tick-borne encephalitis in latvia: land cover, land use, and land ownership. Vector Borne Zoonotic Dis 2010, 10:497-506.

70. Gassner F, Verbaarschot P, Smallegange RC, Spitzen J, Van Wieren SE, Takken W: Variations in Ixodes ricinus density and borrelia infections associated with cattle introduced into a woodland in The Netherlands. Appl Environ Microbiol 2008, 74:7138-7144.

71. Richter D, Matuschka FR: Elimination of lyme disease spirochetes from ticks feeding on domestic ruminants. Appl Environ Microbiol 2010, 76:7650-7652 
72. Daszak P, Cunningham AA, Hyatt AD: Anthropogenic environmental change and the emergence of infectious diseases in wildlife. Acta Trop 2001, 78:103-116.

73. Keesing F, Holt RD, Ostfeld RS: Effects of species diversity on disease risk. Ecol Lett 2006, 9:485-498.

74. Patz JA, Graczyk TK, Geller N, Vittor AY: Effects of environmental change on emerging parasitic diseases. Int J Parasit 2000, 30:1395-1405.

75. Scharf W, Schauer S, Freyburger F, Petrovec M, Schaarschmidt-Kiener D, Liebisch G, Runge M, Ganter M, Kehl A, Dumler JS, et al: Distinct Host Species Correlate with Anaplasma phagocytophilum ankA Gene Clusters. J Clin Microbiol 2011, 49:790-796.

76. Stuen S, Pettersen KS, Granquist EG, Bergstrom K, Bown KJ, Birtles RJ: Anaplasma phagocytophilum variants in sympatric red deer (Cervus elaphus) and sheep in southern Norway. Ticks Tick Borne Dis 2013, 4:197-201.

77. Stuen S: Genetic variants of Anaplasma phagocytophilum in Norway. Int J Med Microbiol 2006, 296:164.

78. Gray JS: The ecology of ticks transmitting Lyme borreliosis. Exp Appl Acarol 1998, 22:249-258

79. Kiffner C, Lodige C, Alings M, Vor T, Ruhe F: Abundance estimation of Ixodes ticks (Acari: Ixodidae) on roe deer (Capreolus capreolus). Exp Appl Acarol 2010, 52:73-84.

80. Li S, Heyman P, Cochez C, Simons L, Vanwambeke SO: A multi-level analysis of the relationship between environmental factors and questing Ixodes ricinus dynamics in Belgium. Parasit Vectors 2012, 5:149.

81. Ostfeld RS, Canham CD, Oggenfuss K, Winchcombe RJ, Keesing F: Climate, deer, rodents, and acorns as determinants of variation in lyme-disease risk. Plos Biology 2006, 4:e145.

82. Robertson JN, Gray JS, Stewart P: Tick bite and Lyme borreliosis risk at a recreational site in England. Eur J Epidemiol 2000, 16:647-652.

83. Vor T, Kiffner C, Hagedorn P, Niedrig M, Ruhe F: Tick burden on European roe deer (Capreolus capreolus). Expl Appl Acarol 2010, 51:405-417.

84. Walker AR, Alberdi MP, Urquhart KA, Rose H: Risk factors in habitats of the tick Ixodes ricinus influencing human exposure to Ehrlichia phagocytophila bacteria. Med Vet Entomol 2001, 15:40-49.

85. Wilson ML, Levine JF, Spielman A: Effect of deer reduction on abundance of the deer tick (Ixodes dammini). Yale J Biol Med 1984, 57:697-705.

86. Gilbert L: Altitudinal patterns of tick and host abundance: a potential role for climate change in regulating tick-borne diseases? Oecologia 2010, 162:217-225.

87. Jensen PM, Hansen H, Frandsen F: Spatial risk assessment for lyme borreliosis Denmark. Scand I Infect Dis 2000, 32:545-550.

88. Ruiz-Fons F, Gilbert $\mathrm{L}$ : The role of deer as vehicles to move ticks, Ixodes ricinus, between contrasting habitats. Int J Parasitol 2010, 40:1013-1020.

89. Bolzoni L, Rosa R, Cagnacci F, Rizzoli A: Effect of deer density on tick infestation of rodents and the hazard of tick-borne encephalitis. II: population and infection models. Int J Parasitol 2012, 42:373-381.

90. Levi T, Kilpatrick AM, Mangel M, Wilmers CC: Deer, predators, and the emergence of Lyme disease. Proc Natl Acad Sci USA 2012, 109:10942-10947.

91. Cattadori IM, Haydon DT, Thirgood SJ, Hudson PJ: Are indirect measures of abundance a useful index of population density? The case of red grouse harvesting. Oikos 2003, 100:439-446.

92. Ranta $\mathrm{E}$, Lindstrom J, Linden $\mathrm{H}$, Helle P: How reliable are harvesting data for analyses of spatio-temporal population dynamics? Oikos 2008, 117:1461-1468.

doi:10.1186/1756-3305-7-11

Cite this article as: Jore et al: Climate and environmental change drives Ixodes ricinus geographical expansion at the northern range margin. Parasites \& Vectors 2014 7:11.

\section{Submit your next manuscript to BioMed Central and take full advantage of:}

- Convenient online submission

- Thorough peer review

- No space constraints or color figure charges

- Immediate publication on acceptance

- Inclusion in PubMed, CAS, Scopus and Google Scholar

- Research which is freely available for redistribution

Submit your manuscript at www.biomedcentral.com/submit
C Biomed Central 